\title{
Nanoparticle-Mediated Drug Delivery for Treatment of Ischemic Heart Disease
}

\author{
Chengming Fan ${ }^{1 *}$, Jyotsna Joshi ${ }^{2 \dagger}$, Fan $\mathrm{Li}^{2}$, Bing $\mathrm{Xu}^{2}$, Mahmood Khan ${ }^{3}$, Jinfu Yang ${ }^{1}$ and \\ Wuqiang Zhu' ${ }^{2,4 *}$
}

\author{
1 Department of Cardiovascular Surgery, The Second Xiangya Hospital, Central South University, Changsha, China, \\ ${ }^{2}$ Department of Cardiovascular Diseases, Mayo Clinic, Scottsdale, AZ, United States, ${ }^{3}$ Department of Emergency Medicine, \\ The Ohio State University Wexner Medical Center, Columbus, OH, United States, ${ }^{4}$ Department of Physiology \\ and Biomedical Engineering, Mayo Clinic, Rochester, MN, United States
}

\section{OPEN ACCESS}

Edited by:

Qingxin $\mathrm{Mu}$,

University of Washington,

United States

Reviewed by:

Nicolas Christoforou,

Pfizer, United States

Deqiang Li,

University of Maryland, Baltimore,

United States

*Correspondence:

Chengming Fan

fchmfchm@163.com

Wuqiang Zhu

Zhu.Wuqiang@mayo.edu

${ }^{\dagger}$ These authors have contributed equally to this work

Specialty section:

This article was submitted to

Nanobiotechnology,

a section of the journal

Frontiers in Bioengineering and

Biotechnology

Received: 04 March 2020

Accepted: 02 June 2020

Published: 24 June 2020

Citation:

Fan C, Joshi J, Li F, Xu B,

Khan M, Yang J and Zhu W (2020) Nanoparticle-Mediated Drug Delivery

for Treatment of Ischemic Heart

Disease.

Front. Bioeng. Biotechnol. 8:687.

doi: 10.3389/fbioe.2020.00687
The regenerative capacity of an adult cardiac tissue is insufficient to repair the massive loss of heart tissue, particularly cardiomyocytes (CMs), following ischemia or other catastrophic myocardial injuries. The delivery methods of therapeutics agents, such as small molecules, growth factors, exosomes, cells, and engineered tissues have significantly advanced in medical science. Furthermore, with the controlled release characteristics, nanoparticle (NP) systems carrying drugs are promising in enhancing the cardioprotective potential of drugs in patients with cardiac ischemic events. NPs can provide sustained exposure precisely to the infarcted heart via direct intramyocardial injection or intravenous injection with active targets. In this review, we present the recent advances and challenges of different types of NPs loaded with agents for the repair of myocardial infarcted heart tissue.

\section{Keywords: nanoparticles, controlled release, myocardial infarction, cardiac repair, drug delivery systems}

\section{INTRODUCTION}

Ischemic heart diseases, caused by coronary artery obstruction, account for almost $80 \%$ of deaths from cardiovascular diseases (Lloyd-Jones et al., 2010). Traditional clinical approaches for myocardial infarction rely on surgical revascularization procedures, such as coronary stenting or coronary artery bypass grafts (CABG). Although the novel therapeutics using cells (especially stem cells) (Gao et al., 2013; Madigan and Atoui, 2018; Terashvili and Bosnjak, 2019), genes (Oggu et al., 2017), exosomes (Davidson and Yellon, 2018), and growth factors (Crafts et al., 2015; Reboucas et al., 2016) are emerging and have shown significant research outcomes, numerous challenges still exist in translating those technologies into clinical practice (Egwim et al., 2017).

Nanoparticles have a long history. Faraday (1857) reported the synthesis of a colloidal Au NP solution for the first time. Similarly, Richard Feynman gave a talk in 1959 describing molecular machines built with atomic precision (Feynman, 1960). These were considered the very first reports on nanotechnology. Metal nanoparticles play a major role in the field of nanoparticle research (Jeevanandam et al., 2018). The 1950s and the 1960s saw the world turning its focus toward the use of nanoparticles in the field of drug delivery. Biological approaches for molecular nanotechnology were the first scientific conference held on the topic in the year 1996 (San Diego, CA, United States). Biological systems are organized at nanoscale dimensions and synthetic nanomaterials correlated in size with biological structures such as proteins, glycolipids, and DNA (Singh et al., 2011). Nanoparticles (NPs) are a type of nano-sized vesicles and can act as a sustained 
release delivery system of therapeutic agents and provide enhanced myocardial recovery in ischemic heart diseases (Binsalamah et al., 2011; Oduk et al., 2018). Nanoparticles can be classified either as organic (Figures 1A,B), inorganic (Figures 1C-G), or hybrid. Organic NPs usually show good biocompatibility, whereas inorganic NPs provide advantages in tailoring varied functions and properties (Vinhas et al., 2017). Organic nanoparticles are fabricated from proteins, carbohydrates, lipids, and other organic compounds to a characteristic dimension, such as a radius around $100 \mathrm{~nm}$ (Pan and Zhong, 2016), and are widely used NPs in cardiac therapy (Table 1). Inorganic NPs include carbon-based NPs, such as carbon nanotubes, buckyballs, and graphene, with remarkable features, strength and unique electrical properties (conducting, semiconducting, or insulating) (Vinhas et al., 2017). Besides, these inorganic NPs also include metal NPs, made of gold, silver, and iron oxide (Vinhas et al., 2017). Table 2 lists recent studies that used inorganic NPs for cardiac therapy. In the organicinorganic hybrid nanoparticles, the organic functional groups combine the unique properties of the inorganic counterparts to confer efficient utility for various in vivo biomedical and clinical applications (Haque and Chowdhury, 2018). The use of hybrid nanoparticles for the slow release of drugs has been gaining great interest, particularly, to improve the selectivity and efficacy of the drugs by combining features of both organic and inorganic components in one nanoparticle system (Table 3 ).

Here, we review the studies done over the last 10 years that investigated the applications of different NP types for repairing cardiac tissue after myocardial infarction and also summarize treatment efficacies of different NP types. Furthermore, some of the advances, challenges, and future strategies in this field are also provided.

\section{ORGANIC NANOPARTICLES}

\section{Lipid-Based NPs}

Typical lipid-based NP formulations (Figure 1A) include solidlipid nanoparticles, nanostructured lipid carriers, lipid-drug conjugates, and nanoemulsions; all are primarily comprised of physiological lipid analogs with surfactants as stabilizers (Qi J. et al., 2017). According to the size of lipid-based nanoparticles, they are named as micelles $(\sim 15 \mathrm{~nm})$, liposomes $(\sim 100 \mathrm{~nm})$ or polymeric NPs (Paulis et al., 2012; Vinhas et al., 2017). Micelles consist of lipids and other amphiphilic artificial molecules that self-assemble in aqueous solution and form a monolayer with the hydrophobic phase inside that incorporates hydrophobic therapeutic agents (Katsuki et al., 2017). The enclosed space in the micelle is more confined than that in liposomes (Katsuki et al., 2017). Liposomes are heavily investigated in nanomedicine and are the first to get FDA approval for nanomedicine (Katsuki et al., 2017; Vinhas et al., 2017). Liposomes mainly consist of phospholipids that form bilayers with the aqueous phase inside, conferring superior biocompatibility to the liposomes (Katsuki et al., 2017). Polymeric nanoparticles, such as polylactic acid (PLA), polyglycolic acid (PGA), and poly lactic-co-glycolic acid (PLGA) are FDA-approved polymers. PLGA is a copolymer of
PLA and PGA and is being tested for drug delivery systems for intractable diseases, including cardiovascular diseases (PascualGil et al., 2017; Oduk et al., 2018).

Lipid NPs are broadly considered as promising candidates for the delivery of therapeutics in the infarcted heart. They possess morphology similar to that of cell membranes and can incorporate both lipophilic and hydrophilic substances (Saludas et al., 2018). They have successfully demonstrated the ability to deliver several biomaterials in the target tissue, such as low molecular weight drugs, imaging agents, peptides, proteins, and nucleic acids (Cheraghi et al., 2017). Paulis et al. (2012) reported that micelles are promising vehicles for the delivery of cardioprotective drugs, needed for the acute stage of $\mathrm{MI}$, and also for the delivery of drugs that regulate infarct healing during the chronic stage of MI. On the other hand, liposomes are more suited for the delivery of pro-angiogenic drugs to the infarct microvasculature (Paulis et al., 2012).

\section{Dendrimers}

Dendrimers (Figure 1B) are the smallest of all the nanocarriers and they have their multiple end groups that are appropriate for a high degree of link targeting or the active agents (Morgan et al., 2005). Dendrimers are dendritically expanded macromolecules with monodisperse structure consisting of a central core, branching interior and exterior functional groups (Morgan et al., 2005). Dendrimers possess the advantage of enhancing the binding capacity upon modification of their exterior surface with some ligands or antibodies for active targeting (Thomas et al., 2013); also, they can carry drugs with poor solubility (Singh et al., 2016). Xue et al. (2018) reported that cardiomyocyte apoptosis and infraction size were significantly reduced following single intravenous administration of dendrimer $(15 \mu \mathrm{g})$, loaded with microRNA-1 inhibitor, in the acute mice MI model.

Selective studies using organic nanoparticles for the delivery of therapeutics to repair infarcted myocardial tissue were listed as Table 1. Paulis et al. (2012) reported that micelles are promising vehicles for the delivery of cardioprotective drugs, needed for the acute stage of MI, and also for the delivery of drugs that regulate infarct healing during the chronic stage of MI. On the other hand, liposomes are more suited for the delivery of pro-angiogenic drugs to the infarct microvasculature. However, to achieve cardiac protection after myocardial infarction, some therapeutic cargoes were required. So far, a large number of agents were loaded into nanoparticles targeted for different purposes. Recent studies have demonstrated that encapsulating ROS, Puerarin or Baicalin into micelles or lipids to reduce infarct size of the animals' ischemic heart (Zhang et al., 2016; Dong et al., 2017; Vong et al., 2018). For cardiomyocyte apoptosis prevention, IGF1, liraglutide, Nitroxyl radical, Cyclosporine A, Pitavastatin or 2,2,6,6-tetramethyl piperidine-1-oxyl was embarked on lipidbased NPs and sent to the animals' ischemic heart (Chang et al., 2013; Yin et al., 2014; Asanuma et al., 2017; Mao et al., 2017; Qi Q. et al., 2017). Intravenous injection of collapsin response mediator protein-2 (CRMP2) lipid with the size of $50 \mathrm{~nm}$ was shown fibrosis reducing in the mice chronic MI heart (Zhou et al., 2015). For vasculogenesis enhancement, VEGF, FGF1, Ang1, stromal cell-derived factor-1 (SDF-1) or CCR2 was loaded in 
A
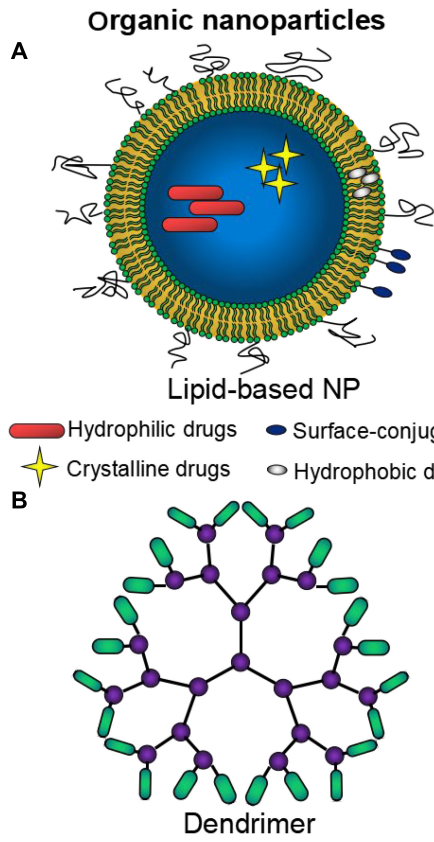

c

\section{Inorganic nanoparticles}

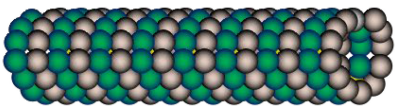

Carbon nanotube

D

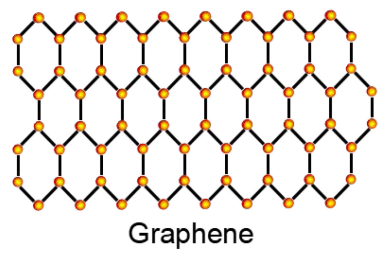

E

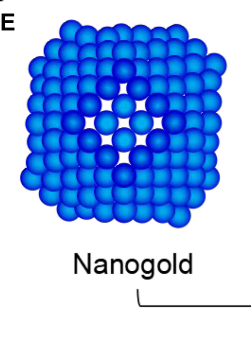

F

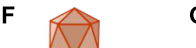

G

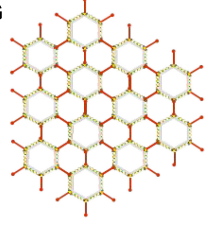

$\mathrm{CeO}_{2} \mathrm{NP}$

FIGURE 1 | Types of nanoparticles commonly used in cardiac therapeutic studies. A wide variety of NPs: organic (A,B), inorganic (C-G) and hybrid NPs are commonly used. Organic nanoparticles (NPs) are fabricated from proteins, carbohydrates, lipids (A), and other organic compounds (B), to a characteristic dimension. Inorganic NPs include carbon-based NPs e.g., carbon nanotubes (C), graphene (D) and metal NPs e.g., gold (E), silver (F), and iron oxide (G).

NPs and delivered to the ischemic myocardial tissue to stimulate angiogenesis (Paul et al., 2011; Lu et al., 2015; Oduk et al., 2018; Ding et al., 2020; Fan et al., 2020). Interestingly, Wang et al. (2018) recently reported that no statistically significant improvements in cardiac function and infarct size were detected in mice acute MI heart with the intravenous administration of CCR2 targeting-nanoparticles (micelles) vs. non-targeted micelles. Recently, nanoparticle delivery through intravenous injection with targeting peptides has merged has a promising strategy. Xue et al. (2018) reported an early targeting therapy for myocardial infarcted mouse through the tail vein with anti-miR-1 antisense oligonucleotide (AMO-1) loaded and myocardiumtargeting dendrimer: PEGylated dendrigraft poly-L-lysine with angiotensin II type 1 receptor (AT1-PEG-DGL AMO-1). They found that AT1-PEG-DGL quickly accumulated in the MI heart during the desired early period, significantly outperforming the group without AT1 targeting. Apoptotic cell death in the infarct border zone was significantly decreased and the myocardial infarct size was reduced by $64.1 \%$ with a single IV injection as compared with that in MI group (Xue et al., 2018).

\section{INORGANIC NANOPARTICLES}

\section{Carbon-Based Nanoparticles}

\section{Carbon Nanotubes}

Carbon nanotubes (CNT) (Figure 1C) are a subfamily of fullerenes and are composed of graphite sheets that are rolled up into tubular forms (Katsuki et al., 2017). As nano-carriers, they incorporate drugs in their inner space and present chemically modified external surfaces with biological molecules, such as nucleotides and proteins, to provide selective targeting (Katsuki et al., 2017). Based on their number of layers, carbon nanotubes are categorized as either single-walled or multi-walled (Sajid et al., 2016). The poor solubility of drugs, faster deactivation, and limited bioavailability can be addressed by using these carbon nanotubes which are preferentially used as drug carriers (Raphey et al., 2019). However, one of the major disadvantages of the CNT is the chance for their dissociation in biological fluids (Raphey et al., 2019). Nevertheless, carbon nanotube is a wellsuited drug carrier for enhanced penetration in the cells and also for offering privileged drug actions (Zhang et al., 2011). Their unique optical, electrical, and mechanical properties make them a suitable candidate for potential therapeutic applications (Gorain et al., 2018). Moreover, a couple of studies have validated the promising potentials of CNT in cardiac tissue engineering, such as in the support of cardiomyocyte function and growth (Ahadian et al., 2017; Sun et al., 2017a) and acceleration of the gap junction formation (Martinelli et al., 2013; Shin et al., 2013). Aside these studies, other investigations have suggested that scaffold consisting of col-hydrogel and CNT could be promising injectable biomaterial to deliver drugs and cells for cardiac tissue regeneration in the infarcted myocardial tissues (Sun et al., 2017b; Gorain et al., 2018).

\section{Graphene}

The nanotechnology field is in constant research of novel materials that can be engineered for the precise, sensitive, and selective detection of biomarkers (Tang et al., 2020). Recently, the graphene-based family of materials has shown huge potential 
as their proposed biosensing applications have shown great diversity (Stankovich et al., 2006; Geim and Novoselov, 2007; Bitounis et al., 2013). The isolated two dimensional (2D) crystal structures composed of single atomic layers of graphite are called "graphene" (Figure 1D; Bitounis et al., 2013). In Novoselov et al. (2004) isolated and characterized a single sheet of graphene. Since then, research on graphene has been highly increasing and has attracted a deep interest in scientific fields (Bitounis et al., 2013; Paul et al., 2014). Feng et al. (2011) pioneered the successful use of graphene as a non-toxic nano-vehicle for efficient gene transfection. With all atoms exposed on its surface, graphene has an ultra-high surface area available for efficient loading of aromatic drug molecules via $\pi-\pi$ stacking, providing a plethora of applications in drug delivery via stable complex formation and avoiding chemical conjugation (Sun et al., 2008; Zhang et al., 2010). Paul et al. (2014) reported that methacrylated gelatin hydrogel (GelMA) impregnated with functionalized graphene oxide (fGO) nanosheets, where the latter were complexed with pro-angiogenic human vascular endothelial growth factor plasmid DNA (pDNAVEGF), formed nanocomposite hydrogels (fGOVEGF/GelMA) that efficiently transfect the myocardial tissues and induce favorable therapeutic effects without invoking adverse cytotoxic effects. Nevertheless, adverse reactions induced by graphene-based materials on exposure will depend on multiple factors that need to be scrutinized (Bitounis et al., 2013). Therefore, clinical translation of graphene-based materials is still in its infancy, yet the field holds tremendous potential for the treatment of multiple diseases (Bitounis et al., 2013).

\section{Metal Nanoparticles}

Nanogold, also called gold nanoparticles (GNPs) or colloidal gold (Figure 1E), has been actively investigated in a wide variety of biomedical applications (Zhou Y. et al., 2018). The unique physical and chemical properties, such as ease of bioconjugation, excellent stability, superior security, and strong biocompatibility of many GNPs make them promising candidates in nanomedicine (Sperling et al., 2008).

Silver nanoparticles (AgNPs) (Figure 1F) have been developed as potent anti-microbial agents and have a multitude of applications, such as in toothpastes, bedding, water purification, and nursing bottles (Priyadarsini et al., 2018). After oral exposure, it is shown that about $18 \%$ of silver could be absorbed in humans (Bostan et al., 2016). Animal studies showed that AgNPs exposure will cause enhanced superoxide anion production and cause deleterious effects in cardiac tissues (Ebabe Elle et al., 2013; Lin et al., 2017; Xu et al., 2018). Thus, toxicity concerns of AgNPs have limited their effective translation for the cardiac tissue repair.

Cerium oxide $\left(\mathrm{CeO}_{2}\right)$ nanoparticles (Figure 1G) have wide applications, such as in oxygen sensors and automotive catalytic converters (Niu et al., 2011). These nanoparticles are considered potent remedial options for the treatment of smoking-related diseases (El Shaer et al., 2017) since intravenous injection of these nanoparticles have shown a marked reduction in the myocardial oxidative stress and have also shown a significant reduction of the left ventricular dysfunction in the murine models of heart failure (Niu et al., 2011). The well-known mechanism underlying the action of these nanoparticles is attributed to their dual oxidation state, where the loss of oxygen and the reduction of $\mathrm{Ce}^{4+}$ to $\mathrm{Ce}^{3+}$ are accompanied by the creation of an oxygen vacancy (Niu et al., 2007).

Selective studies using inorganic nanoparticles for the delivery of therapeutics to repair infarcted myocardial tissue were listed as Table 2. Unlike the organic nanoparticles, the inorganic nanomaterials alone (without therapeutic agents loaded) could provide mechanical support even enhance cell electrical signaling in some conducting nanomaterials (Zhou J. et al., 2018). Zhou et al., created a conductive hydrogel by introducing graphene oxide (GO) nanoparticles into oligo(poly(ethylene glycol) fumarate) (OPF) hydrogels and delivered to the Sprague Dawley rats' acute MI heart by peri-infarct intramyocardial injection. They found that injected OPF/GO hydrogels can not only provide mechanical support but also electric connection between normal cardiomyocytes and the myocardium in the scar via activating the canonical Wnt signaling pathway, thus upregulating the generation of $\mathrm{Cx} 43$ and gap junction-associated proteins (Zhou J. et al., 2018). However, inorganic nanoparticles loaded with potential therapeutic agents have been widely studied. Similar to the studies of organic nanoparticles, scholars mainly aim at oxidative stress-reducing, inflammation attenuation, cardiomyocyte apoptosis prevention, fibrosis reducing and vasculogenesis enhancement (Han et al., 2018; Sharma et al., 2018). Copper has shown the anti-inflammatory, anti-oxidant potential and cardioprotective effect. Sharma et al. treated treat the I/R rat with low dose copper nanoparticles (CuNP) (1 mg/kg/day, p.o., 4 weeks) and myocardial protection was detected like the reduction of oxidative stress, inflammatory cytokines and apoptosis through phosphorylate GSK-3 $\beta$ kinase pathways (Sharma et al., 2018). Gold nanoparticles (AuNPs) delivered intravenously (400 $\mu \mathrm{g} / \mathrm{kg} /$ day, 14 consecutive days) may also improve myocardial injury after myocardial infarction in rats with the decrease of eNOs immunoreaction, Bcl-2 and collagen fibers (Ahmed et al., 2017). However, in another mouse acute MI model, AuNPs intravenous administration (100 $\mu \mathrm{l} /$ day, 7 days) accumulated in infarcted hearts, decreased infarction size, inhibited cardiac fibrosis but has no effect on apoptosis and hypertrophy (Tian et al., 2018). Inflammation attenuation was shown in mouse MI models intramyocardial injection of $50 \mu \mathrm{l}$ interleukin-4 plasmid DNA-functionalized macrophagetargeting graphene oxide complex (MGC/IL-4 pDNA) via a reduction in intracellular ROS and developing M2 macrophage phenotypes in macrophages (Han et al., 2018). Similar to the organic nanoparticles, intramyocardial injection of a nanocomplex of graphene oxide loaded with vascular endothelial growth factor-165 (VEGF) gene in the rat acute MI model shows significant infarct size reduction and capillary density enhancement (Paul et al., 2014). Further studies are needed to elucidate the long-term biocompatibility and safety of these inorganic nanoparticles.

\section{ORGANIC-INORGANIC HYBRID NANOPARTICLES}

Recently, interests in the applications of various organicinorganic hybrid nanoparticles (NPs) have risen tremendously. 
TABLE 1 | List of selective studies using organic nanoparticles for the delivery of therapeutics to repair infarcted myocardial tissue.

\begin{tabular}{|c|c|c|c|c|c|}
\hline $\begin{array}{l}\text { Nanoparticles/ } \\
\text { size }(\mathrm{nm})\end{array}$ & Therapeutic agents & MI Model & Dose/administration route & Results & References \\
\hline $\begin{array}{l}\text { Micelle/14.9 } \\
\text { Liposome/101.5 }\end{array}$ & None & $\begin{array}{l}\text { Mouse, acute } \\
\text { and chronic }\end{array}$ & $50 \mu \mathrm{mol} \mathrm{Gd} / \mathrm{kg}$, intravenous & $\begin{array}{l}\text { Micelles permeated the entire infarct area, Liposomes showed slower } \\
\text { and restricted extravasation from the vasculature }\end{array}$ & Paulis et al., 2012 \\
\hline Micelles/ 90-100 & ROS & Mouse, acute & $3 \mathrm{mg}$, intramyocardial & Reduced infarct size and improved heart functions & Vong et al., 2018 \\
\hline PEG-PLGA/350 & Liraglutide & Rat, chronic & $380 \mu \mathrm{g}$, intramyocardial & $\begin{array}{l}\text { Reduced infarct size, preserved wall thickness, stimulated } \\
\text { angiogenesis, prevented cardiomyocyte apoptosis and improved heart } \\
\text { functions }\end{array}$ & Qi Q. et al., 2017 \\
\hline PLGA/113 & VEGF & Mouse, chronic & $\begin{array}{l}0.06,2.6 \text { or } 0.6 \mathrm{pg} \text {, } \\
\text { intramyocardial }\end{array}$ & $\begin{array}{l}\text { Improved heart function, increased wall thickness, reduced infarct size } \\
\text { and vasculogenesis }\end{array}$ & Oduk et al., 2018 \\
\hline PLGA/75 & IGF1 & Mouse, chronic & 20 ng, intramyocardial & $\begin{array}{l}\text { Prevented cardiomyocyte apoptosis, reduced infarct size, improved LV } \\
\text { function and cardiac geometry }\end{array}$ & Chang et al., 2013 \\
\hline PK3/500 & Nox2-siRNA & Mouse, chronic & 5 ug/kg, intramyocardial & Improved fractional shortening & $\begin{array}{l}\text { Somasuntharam et al., } \\
2013\end{array}$ \\
\hline PK3/500 & Nox2-miRNA & Mouse, chronic & $5 \mathrm{ug} / \mathrm{kg}$, intramyocardial & Improved fractional shortening and ejection fraction, reduced infarct size & Yang et al., 2017 \\
\hline Micelles/40 & Nitroxyl radical & Dog, l/R & $3 \mathrm{mg} / \mathrm{kg}$, intravenous & Reduced infarct size and myocardial apoptosis & Asanuma et al., 2017 \\
\hline Micelles/ $34.7 \pm 14$ & CCR2 & Mouse, acute & $33 \mathrm{mg} / \mathrm{kg}$, intravenous & $\begin{array}{l}\text { No statistically significant improvements in cardiac function and infarct } \\
\text { size }\end{array}$ & Wang et al., 2018 \\
\hline Silicon/ 100-200 & siRNA, CCR2, MSCs & Mouse, chronic & $\begin{array}{l}25 \mathrm{mg} / \mathrm{kg} 1 \times 10^{5} \text { cells, } \\
\text { intravenous }\end{array}$ & Improved LV remodeling amelioration and vascular density & Lu et al., 2015 \\
\hline Lipid/ 50 & SiRNA CRMP2 & Mouse, chronic & $70 \mu \mathrm{g} / \mathrm{kg}$, intravenous & Reduced post-MI heart failure, mortality and fibrosis & Zhou J. et al., 2018 \\
\hline Lipid/ $<160$ & Cyclosporine A, ADSCs & Pig, chronic & $\begin{array}{l}2 \mathrm{mg} / \mathrm{kg} 4 \times 10^{7} \text { cells, } \\
\text { intravenous }\end{array}$ & $\begin{array}{l}\text { Improved heart function, reduced infarct size and cardiomyocyte } \\
\text { apoptosis }\end{array}$ & Yin et al., 2014 \\
\hline Silicon/ 180 & ERK1/2 inhibitor & Rat, acute & $33 \mu \mathrm{g}$, intravenous & Reduced hypertrophy & Ferreira et al., 2017 \\
\hline PLGA 100 & Cyclosporine A & Mouse, $1 / R$ & $1 \mathrm{mg} / \mathrm{kg}$, intravenous & Improved LV remodeling & Ikeda et al., 2016 \\
\hline PLGA 200 & Irbesartan & Mouse, I/R & $3 \mathrm{mg} / \mathrm{kg}$, intravenous & Reduced infarct size and LV remodeling & Nakano et al., 2016 \\
\hline PLGA 160 & Pitavastatin & Rat, l/R & $1 \mathrm{mg} / \mathrm{kg}$, intravenous & Reduced cardiomyocyte apoptosis & Mao et al., 2017 \\
\hline PLGA 160 & Pitavastatin & Mouse, $1 / R$ & $1 \mathrm{mg} / \mathrm{kg}$, intravenous & Improved LV remodeling & Nagaoka et al., 2015 \\
\hline PLGA 160 & Pitavastatin & Pig, l/R & 8-32 mg/kg, intravenous & $\begin{array}{l}\text { Improved LV remodeling, reduced infarct size and cardiomyocyte } \\
\text { apoptosis }\end{array}$ & Ichimura et al., 2016 \\
\hline $\mathrm{PEI} / 45$ & $\begin{array}{l}\text { siRNA Icam1, Icam1, } \\
\text { Vcam1, Sele and Selp }\end{array}$ & Mouse, chronic & $1 \mathrm{mg} / \mathrm{kg}$, intravenous & Reduced matrix-degrading protease activity & Sager et al., 2016 \\
\hline Lipid/110 & Puerarin & Rat, chronic & $50 \mathrm{mg} / \mathrm{kg}$, intravenous & Reduced infarct size and oxidative stress & Dong et al., 2017 \\
\hline Lipid/84 & Baicalin & Rat, chronic & $10 \mathrm{mg} / \mathrm{kg}$, intravenous & Reduced infarct size and oxidative stress & Zhang et al., 2016 \\
\hline Lipid/130 & Schisandrin B & Rat, chronic & $10 \mathrm{mg} / \mathrm{kg}$, intravenous & Reduced infarct size & Shao et al., 2017 \\
\hline Lipid/<1000 & Hemin & Mouse, chronic & $2 \mathrm{mg} / \mathrm{kg}$, intravenous & Improved infarct healing and repair & $\begin{array}{l}\text { Ben-Mordechai et al., } \\
2017\end{array}$ \\
\hline Lipid/105 & Flavonoid & Rat, l/R & $\begin{array}{l}0.29 \text { drug/lipid ratio, } \\
\text { intravenous }\end{array}$ & Reduced infarct size & Tan et al., 2017 \\
\hline $\begin{array}{l}\text { PEG-poly } \\
\text { oxymethyl } \\
\text { estyrene/40 }\end{array}$ & $\begin{array}{l}\text { 2,2,6,6-tetramethyl } \\
\text { piperidine-1-oxyl }\end{array}$ & Dog, $1 / R$ & $3 \mathrm{mg} / \mathrm{kg}$, intravenous & Reduced infarct size, apoptosis and ventricular fibrillation & Asanuma et al., 2017 \\
\hline Micellar/- & Rapamycin & $\begin{array}{l}\text { Diabetic } \\
\text { mouse, } 1 / R\end{array}$ & $\begin{array}{l}0.75 \mathrm{mg} / \mathrm{kg} / \text { day, p.o. } 10 \text { weeks } \\
\text { before } / / \mathrm{R}\end{array}$ & Improved cardiac functions; reduced infarct size & Samidurai et al., 2017 \\
\hline Dendrimer/50 & microRNA-1 inhibitor & Mouse, acute & $15 \mu \mathrm{g}$, intravenous & Reduced cardiomyocyte apoptosis and infarct size & Xue et al., 2018 \\
\hline
\end{tabular}


TABLE 2 | List of selective studies using inorganic nanoparticles for the delivery of therapeutics to repair infarcted myocardial tissue.

\begin{tabular}{|c|c|c|c|c|c|}
\hline $\begin{array}{l}\text { Nanoparticles/ } \\
\text { size }(\mathrm{nm})\end{array}$ & Therapeutic agents & MI Model & Dose/administration route & Results & References \\
\hline Graphene/30-40 & VEGF & Rat, acute & $300 \mu \mathrm{L}$, intramyocardial & $\begin{array}{l}\text { Reduced infarct size, improved capillary density and cardiac } \\
\text { performance }\end{array}$ & Paul et al., 2014 \\
\hline $\begin{array}{l}\text { OPF/graphene } \\
\text { oxide hydrogel }\end{array}$ & - & Rat, acute & $100 \mu \mathrm{L}$, intramyocardial & $\begin{array}{l}\text { Improved load-dependent ejection fraction/fractional shortening of heart } \\
\text { function }\end{array}$ & Zhou J. et al., 2018 \\
\hline $\begin{array}{l}\text { Graphene oxide } \\
\text { complex/150 }\end{array}$ & $\mathrm{IL}-4 \mathrm{pDNA}$ & Mouse, acute & $50 \mu \mathrm{L}$, intramyocardial & Attenuated inflammation, mitigated fibrosis and improved heart function & Han et al., 2018 \\
\hline Graphene oxide & Mesenchymal stem cell & Rat, I/R & One million MSCs & $\begin{array}{l}\text { Improved the engraftment and therapeutic efficacy of MSCs, which } \\
\text { promoted cardiac tissue repair and cardiac function }\end{array}$ & Park et al., 2015 \\
\hline Gold/10 & PEG coated & Mouse, acute & $100 \mu /$ day, intravenous, 7 days & $\begin{array}{l}\text { Decreased infarct size, improved systolic functions, inhibited cardiac } \\
\text { fibrosis, no effect on apoptosis and hypertrophy }\end{array}$ & Tian et al., 2018 \\
\hline Copper/90-150 & $\mathrm{Cu}$ & Rat, I/R & 1 mg/kg/day, p.o. & $\begin{array}{l}\text { Diminished oxidative stress, inflammatory cytokines and apoptosis, } \\
\text { reduced infarct size }\end{array}$ & Sharma et al., 2018 \\
\hline Gold/50 & $\mathrm{Au}$ & Rat, acute & $\begin{array}{l}\text { ( } 400 \mu \mathrm{g} / \mathrm{kg} / \text { day) intravenous, } \\
14 \text { days }\end{array}$ & Improved myocardial injury & Ahmed et al., 2017 \\
\hline Cerium oxide/4-6 & Ceria & $\begin{array}{l}\text { Isoproterenol } \\
\text { induced Ml rat }\end{array}$ & $\begin{array}{l}\text { ( } 0.5 \text { and } 5 \mathrm{mg} / \mathrm{kg} / \text { week), } \\
\text { Intraperitonial, } 5 \text { weeks }\end{array}$ & Provided prophylactic effect against cardiac toxicity & El Shaer et al., 2017 \\
\hline $\begin{array}{l}\text { Graphene oxide } \\
\text { gold nanosheets } \\
\text { (GO-Au) }\end{array}$ & $\begin{array}{l}\text { chitosan-GO-Au } \\
\text { scaffold }\end{array}$ & Rat, acute & $5 \times 2 \mathrm{~mm}$ scaffold & Improved the cardiac contractility and restored ventricular functions & Saravanan et al., 2018 \\
\hline
\end{tabular}

TABLE 3 | List of selective studies using organic-inorganic nanoparticles for the delivery of therapeutics for the repair of myocardial infracted heart tissue.

\begin{tabular}{|c|c|c|c|c|c|}
\hline $\begin{array}{l}\text { Nanoparticles/ } \\
\text { size }(\mathrm{nm})\end{array}$ & Therapeutic agents & MI Model & Dose/administration route & Results & References \\
\hline $\begin{array}{l}\text { DNAzyme- } \\
\text { conjugated AuNPs/ } \\
14 \pm 3\end{array}$ & Silence TNF- $\alpha$ & Rat, acute & $100 \mu \mathrm{L}$, intramyocardial & Significant anti-inflammatory benefits and improved cardiac function & $\begin{array}{l}\text { Somasuntharam et al., } \\
2016\end{array}$ \\
\hline $\begin{array}{l}\text { Organic-inorganic } \\
\text { hybrid hollow } \\
\text { mesoporous } \\
\text { organosilica } \\
\text { nanoparticles } \\
\text { (HMONs)/20 }\end{array}$ & $\begin{array}{l}\text { Hepatocyte growth } \\
\text { factor (HGF) } \\
\text { gene-transfected } \\
\text { BMMSCs }\end{array}$ & Rat, acute & $\begin{array}{l}2 \times 10^{6} \mathrm{HGF} \text { gene-transfected } \\
\text { BMMSCs, intramyocardial }\end{array}$ & $\begin{array}{l}\text { Decreased apoptotic cardiomyocytes, reduced infarct scar size, } \\
\text { relieved interstitial fibrosis, increased angiogenesis, and improved } \\
\text { cardiac functions }\end{array}$ & Zhu et al., 2016 \\
\hline $\begin{array}{l}\text { Complex of } \\
\text { recombinant } \\
\text { baculovirus and } \\
\text { Tat/DNA } \\
\text { nanoparticles /500 }\end{array}$ & Angiopoietin-1 gene & Rat, acute & $300 \mu \mathrm{L}$, intramyocardial & $\begin{array}{l}\text { Increased capillary density, reduced infarct size and improved cardiac } \\
\text { functions }\end{array}$ & Paul et al., 2011 \\
\hline
\end{tabular}


Hybrid NPs combine features of organic and inorganic building blocks and generate NPs with improved physicochemical properties, such as particle size and surface charge (Haque and Chowdhury, 2018). Hybrid organic-inorganic NPs hold great promise in overcoming the pitfalls being faced by existing inorganic materials in the delivery of therapeutics and contrast agents (Somasuntharam et al., 2016), such as unwanted interactions with serum proteins (particularly opsonins) and consequential removal from the circulation by macrophages of mononuclear phagocytic system, rapid renal clearance, prolonged body accumulation, and lack of targetability (Zhou and Zhang, 2019).

Magnetoliposomes (MLs) are composed of liposomes and magnetic NPs and are the first efficient hybrid liposome/NP systems produced for the drug delivery (Namdari et al., 2017). In this line, several experimental strategies have been investigated the potential scope of magnetic NPs to leverage the delivery of growth factors, cytokines, and biomolecules to the degenerating cardiac cells and tissues and enhance their regeneration (Allen and Cullis, 2013; Paul et al., 2014; Ottersbach et al., 2018).

Selective studies using organic-inorganic nanoparticles for the delivery of therapeutics to repair infarcted myocardial tissue were listed as Table 3. Somasuntharam et al. (2016) created deoxyribozyme (DNAzyme) functionalized AuNPs to catalytically silence tumor necrosis factor- $\alpha(\mathrm{TNF}-\alpha)$ as a potential therapeutic for acute myocardial infarction. After the intramyocardial injection, with the silencing of TNF- $\alpha$, significant anti-inflammatory benefits, and cardiac function improvement were detected in the rat heart. With the same model, (Paul et al., 2011) design a new gene delivery method utilizing a self-assembled binary complex of negatively charged baculovirus (Bac) and positively charged endosomolytic histidine-rich Tat peptide/DNA nanoparticles (NP) together with Angiopoietin-1 (Ang-1) gene carried by. 3 weeks post intramyocardially delivery, cardiac function improvement, capillary density enhancement, and infarct sizes reduction were detected in Bac-NP(Ang1) compared to Bac(Ang1), $\mathrm{NP}$ (Ang1) and control groups due to enhanced myocardial Ang-1 expression at peri-infarct regions. Furthermore, (Zhu et al., 2016) designed and synthesized molecularly organicinorganic hybrid hollow mesoporous organosilica nanoparticles (HMONs) for gene transfection (hepatocyte growth factor, $\mathrm{HGF}$ ) in BMMSCs and subsequent in vivo cardiac repair. The fabricated organic-inorganic hybrid HMONs with large pore size represent a generalizable strategy to promote the ischemic myocardium therapeutic potential of HGF transfected BMMSCs including reduction of apoptotic cardiomyocytes, infarct scar size, and interstitial fibrosis while increasing angiogenesis (Zhu et al., 2016).

\section{ARTIFICIAL DNA NANOSTRUCTURES}

The success of DNA nanotechnology lies in the artificially constructed special nanostructure design systems for DNA computing (Lee et al., 2016). DNA nanostructures, owing to their precise control over chemistry, size, and shape, provide vast opportunity to unfold the convoluted mass of information relating to nanoparticle-biological interactions (Lee et al., 2016). Drug delivery and therapeutics is considered as one of the most promising applications of the structural DNA nanotechnology (Ke et al., 2018). In this line, artificial nucleic acid nano-devices could be utilized to provide targeted drug delivery in the tissues upon sensing their environment (Singh et al., 2016). Moreover, several studies have proposed various DNA nanostructures and strategies to load, deliver, and release biomolecular drugs for cardiac therapy (Paul et al., 2011).

\section{COMPARISON OF THE NANOPARTICLES AS FOR ISCHEMIC MYOCARDIUM REPAIR}

Nanoparticles of different types (for example, inorganic, organic and hybrid) designed to target ischemic cardiac cells are promising candidates for the treatment of myocardial infarction. Organic nanoparticles are offering numerous advantages which embrace the simplicity of their preparation from well-understood biodegradable, biocompatible polymers, and their high stability in biological fluids during storage (Virlan et al., 2016). Since the emergence of nanotechnology in the past decades, polymeric materials such as poly (d-lactic acid), polyethylene glycol (PEG) and poly lacticco-glycolic acid (PLGA) have emerged as a major class of biodegradable and controlled release systems for delivering biomolecules/proteins to the plaque site (Fredman et al., 2015; Kamaly et al., 2016).

The use of inorganic nanoparticles for applications in drug delivery presents a wide array of advantages, which include: (1) Ease of functionality with a range of surface and conjugation chemistries; (2) High payload loadings; (3) Tunable degradation rates; and (4) Enhanced penetration into tissue (Pandey and Dahiya, 2016). Magnetic nanoparticles were shown to accelerate the expression of critical gap junction proteins (for example, connexin 43) in cardiomyoblasts. These new cells demonstrated higher levels of both engraftment capacity and desirable paracrine factors compared with conventional therapeutic cells, thus significantly enhanced heart function and reduced scar size when delivered into the peri-infarcted area in rats (Han et al., 2015). Superparamagnetic iron oxide nanoparticles, with biocompatibility and capacity for simultaneous imaging and targeting, have emerged as the major particles for enhancing the engraftment of therapeutic cells in heart tissue. However, it was recently revealed that these nanoparticles increase tumorassociated macrophage activation (Zanganeh et al., 2016).

Intensive studies have thoroughly probed the toxicities of a wide range of nanoparticles (organic, inorganic, and polymeric) in different types of cells and organs. However, the cardiotoxicity of nanoparticles has been poorly investigated, and data are still limited to a few types of nanoparticle including metal oxides, silver, and carbon (Bostan et al., 2016). The main limiting issue for the design of safe and efficient nanoparticles for the treatment of ischemic heart disease is the lack of a deep understanding of the biological identity of nanoparticles. To accelerate the clinical translation of nanoparticles for use in cardiac nanotechnology, 
TABLE 4 | Advantages and disadvantages of different nanoparticles for the delivery of therapeutics to repair infarcted myocardial tissue.

\begin{tabular}{|c|c|c|c|}
\hline Type & Advantages & Disadvantages & References \\
\hline Lipid-based NPs & $\begin{array}{l}\text { Increased penetration and/or permeation, } \\
\text { Biocompatible and biodegradable nature, Easy and } \\
\text { scalable production process, Increased drug }\end{array}$ & $\begin{array}{l}\text { Loss of high amounts of drug, Lack of robust controlled } \\
\text { drug release, Burst drug release may induce toxic } \\
\text { effects, Macrophage drug clearance (rapid clearance). }\end{array}$ & $\begin{array}{l}\text { Ghasemiyeh and } \\
\text { Mohammadi-Samani, } \\
2018\end{array}$ \\
\hline
\end{tabular}

Dendrimers

Carbon Nanotubes

Metal Nanoparticles solubility, Possibility of specific follicular targeting, Good stability during storage period.

Ease of fabrication, targeting ability, potential for repeat administration, low immune response and precise controllability of the functionality.

Great batch-to-batch variability and deterioration, the attachment of multiple molecules can often result in a population of conjugates with a wide distribution of the number of ligands.

Still don't understand how they work, Difficult to work with, Toxic qualities, Lack of solubility in most solvents,

Extremely small and lightweight, Resources required are plentiful, Resistant to temperature changes, Highly flexible and elastic, and Improve conductive mechanical properties.

Susceptibility to oxidative environments, Difficulty in maintaining high quality and minimal impurities. Instability, impurity, explosion and safety concerns Strong plasma absorption, Biological system imaging, Determine chemical information on metallic nanoscale substrate.

Pitroda et al., 2016

Harish et al., 2018
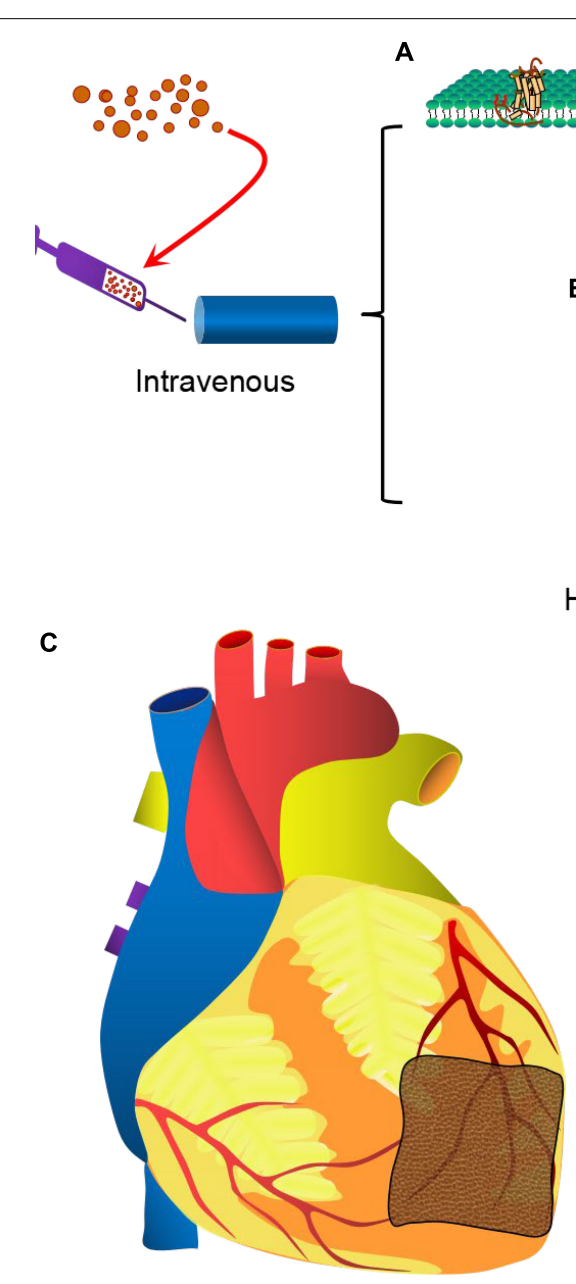

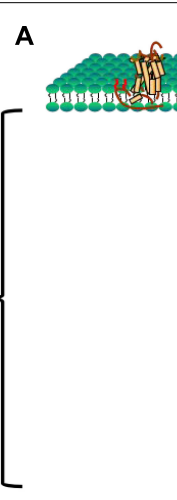

B

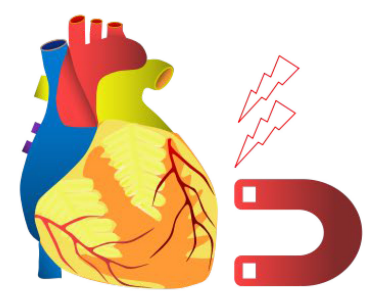

Heating/Magnetic guidance
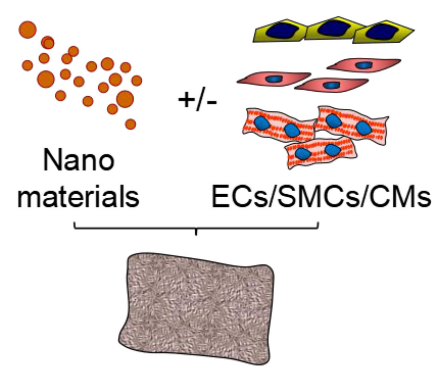

Patch
Heart-targeted agents

(n)

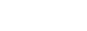

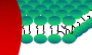

atso 
their biological identities must be precisely assessed and reported (Mahmoudi et al., 2017). The advantage and disadvantage of each NP category were summarized in Table 4.

\section{CLINICAL APPLICATION}

A large number of patents, pertinent to the invention of cardiovascular biomaterials, have been filed in the past decade. Importantly, an invention of the UV-crosslinkable gelatin methacrylate-based cardiac patch, impregnated with gold nano-rods, was recently patented (US20170143871 A1). The patent describes about patch that exhibits high surface area and electrical conductivity. Another recent invention describes a combination of gold nano-wires and engineered scaffolds for controlling the cellular function through electronic circuits (US20170072109 A1). Furthermore, a new strategy of nanoparticle-stem cell electrostatically conjugates for postinfarction treatment was patented in Japan (JP5495215 B2). A preparation method of nanomagnetic particles for the detection and treatment of coronary heart diseases was patented in China (CN102085380A). This method can be used for preparing magnetic nanoparticles for mid-late-stage treatment of coronary heart diseases; and good repairing and treatment effects on coronary heart diseases can be achieved. In another patent, a solid lipid nanoparticle of Gelan Xinning Ruanjiaonang (Chinese traditional medicine) for treating coronary heart disease was created and beneficial for clinical application (CN103027981B). The treatment effect of Gelan Xinning Ruanjiaonang for coronary heart disease is significantly improved with the solid lipid nanoparticle included. Despite several patented technologies for cardiovascular therapeutics, only a few have entered into the clinical trials, due to the stringent regulatory requirements (Lakshmanan and Maulik, 2018). Fortunately, some of the targeted drug nanocarriers for cardiac therapies successfully passed clinical trials (Galagudza et al., 2010) and are already commercially available (Chong et al., 2014). For instance, one of the clinical strategies that has been practiced since long for inducing angiogenesis in the ischemic tissues includes intramuscular transplantation of the micro-bubbles and causing ultrasound-mediated microbubble destruction for the delivery of entrapped bone marrow-derived mononuclear cells (BM-MNCs) to provide tissue regeneration (Tateishi-Yuyama et al., 2002).

\section{CURRENT STATE-OF-THE-ART NANOTECHNOLOGY USED IN CARDIAC THERAPY AND FUTURE PERSPECTIVES}

Despite initial encouraging results from nanotechnology-based cardiac protection, poor retention time, efficacy, side effects or off-target effects of the delivered NPs remain major obstacles for efficient myocardial regeneration (Chang et al., 2013; Somasuntharam et al., 2013; Yin et al., 2014; Zhou et al., 2015). Several delivery strategies like intracoronary, intramyocardial, or intravenous have been applied for cardiac repair. Traditionally, NPs were injected via intracoronary or intramyocardial route and they rely on open heart surgery (Chang et al., 2013; Somasuntharam et al., 2013). Most adverse effects were observed they were delivered either intravenously or orally (Yin et al., 2014; Zhou et al., 2015). So far, no strategy has been proven to replace the transmural scar tissue in the chronic infarcted heart tissues. However, the current state-of-the-art nanoparticle technologies have emerged as one of the most promising strategies for myocardial repair (Awada et al., 2016). With the application of heart targeted agents, efficacy could be highly improved, while lowering the adverse effects by delivering NPs by intravenous route (Nguyen J. et al., 2015; Ferreira et al., 2016). The active targeting agents include MMP-2 and MMP-9 targeting peptides (Nguyen M. M. et al., 2015), which may results in long-term retention at the site of infarction. The atrial natriuretic peptide (ANP) is a circulating cardiac hormone produced physiologically, which belongs to the natriuretic peptide family and has been shown to have cardioprotective properties through cGMP-dependent signaling involving guanylyl cyclase A (GC-A) receptors (Potter et al., 2009). Peptide CSTSMLKAC and CRSWNKADNRSC are cyclic structures and have shown alone selective targeting to the ischemic heart (Kanki et al., 2011; Ferreira et al., 2016). Furthermore, heart homing agents make oral administration or inhalation administration an alternative and promising approach (Miragoli et al., 2018; Sharma et al., 2018).

The majority of the in vivo studies have shown the great potential of the nanoparticle systems in improving the function and tissue regeneration of the infarcted myocardium. However, further improvement in the homing and delivery of these nanoparticles and their therapeutic effects, respectively, to the target tissues can be achieved via decoration of these nanoparticle systems using heart-targeting active molecules (Figure 2A) or using non-invasive physical cues (Figure 2B). Furthermore, future clinical strategy may involve the application of cardiac patch that not only delivers the therapeutic agents, but its scaffolding effect provides optimal mechanical support to the failing heart and also replaces lost cells and tissues with induced pluripotent stem cell-derived cardiovascular cells, such as cardiomyocytes, endothelial cells and smooth muscle cells (Figure 2C). Thus, it is expected that advances in drug therapy, nanomedicine, cell-therapy, and material science will provide robust functional improvement and tissue restoration in patients with myocardial infarction in the near future.

\section{AUTHOR CONTRIBUTIONS}

CF, JJ, and WZ wrote the manuscript. FL, BX, MK, JY, and WZ, revised the manuscript. All authors approved the submission and publication of the manuscript.

\section{FUNDING}

This work was supported by the National Institutes of Health (National Heart, Lung, and Blood Institute R01 
grant HL142627 to WZ and R01HL136232 to MK), and the American Heart Association Scientist Development Grant (16SDG30410018 to WZ). CF was supported by the Fundamental Research Funds from the Central South University (2017zzts234).

\section{REFERENCES}

Ahadian, S., Davenport Huyer, L., Estili, M., Yee, B., Smith, N., Xu, Z., et al. (2017). Moldable elastomeric polyester-carbon nanotube scaffolds for cardiac tissue engineering. Acta Biomater. 52, 81-91. doi: 10.1016/j.actbio.2016.12.009

Ahmed, S. M., Abdelrahman, S. A., and Salama, A. E. (2017). Efficacy of gold nanoparticles against isoproterenol induced acute myocardial infarction in adult male albino rats. Ultrastruct. Pathol. 41, 168-185. doi: 10.1080/01913123. 2017.1281367

Allen, T. M., and Cullis, P. R. (2013). Liposomal drug delivery systems: from concept to clinical applications. Adv. Drug Deliv. Rev. 65, 36-48. doi: 10.1016/ j.addr.2012.09.037

Asanuma, H., Sanada, S., Yoshitomi, T., Sasaki, H., Takahama, H., Ihara, M., et al. (2017). Novel synthesized radical-containing nanoparticles limit infarct size following ischemia and reperfusion in canine hearts. Cardiovasc. Drugs Ther. 31, 501-510. doi: 10.1007/s10557-017-6758-6

Awada, H. K., Hwang, M. P., and Wang, Y. (2016). Towards comprehensive cardiac repair and regeneration after myocardial infarction: aspects to consider and proteins to deliver. Biomaterials 82, 94-112. doi: 10.1016/j.biomaterials.2015. 12.025

Ben-Mordechai, T., Kain, D., Holbova, R., Landa, N., Levin, L. P., Elron-Gross, I., et al. (2017). Targeting and modulating infarct macrophages with hemin formulated in designed lipid-based particles improves cardiac remodeling and function. J. Control Release 257, 21-31. doi: 10.1016/j.jconrel.2017.01.001

Binsalamah, Z. M., Paul, A., Khan, A. A., Prakash, S., and Shum-Tim, D. (2011). Intramyocardial sustained delivery of placental growth factor using nanoparticles as a vehicle for delivery in the rat infarct model. Int. J. Nanomed. 6, 2667-2678.

Bitounis, D., Ali-Boucetta, H., Hong, B. H., Min, D. H., and Kostarelos, K. (2013). Prospects and challenges of graphene in biomedical applications. Adv. Mater. 25, 2258-2268. doi: 10.1002/adma.201203700

Bostan, H. B., Rezaee, R., Valokala, M. G., Tsarouhas, K., Golokhvast, K., Tsatsakis, A. M., et al. (2016). Cardiotoxicity of nano-particles. Life Sci. 165, 91-99. doi: 10.1016/j.lfs.2016.09.017

Chang, M. Y., Yang, Y. J., Chang, C. H., Tang, A. C., Liao, W. Y., Cheng, F. Y., et al. (2013). Functionalized nanoparticles provide early cardioprotection after acute myocardial infarction. J. Control Release 170, 287-294. doi: 10.1016/j.jconrel. 2013.04.022

Cheraghi, M., Negahdari, B., Daraee, H., and Eatemadi, A. (2017). Heart targeted nanoliposomal/nanoparticles drug delivery: an updated review. Biomed. Pharmacother. 86, 316-323. doi: 10.1016/j.biopha.2016.12.009

Chong, J. J., Yang, X., Don, C. W., Minami, E., Liu, Y. W., Weyers, J. J., et al. (2014). Human embryonic-stem-cell-derived cardiomyocytes regenerate non-human primate hearts. Nature 510, 273-277.

Crafts, T. D., Jensen, A. R., Blocher-Smith, E. C., and Markel, T. A. (2015). Vascular endothelial growth factor: therapeutic possibilities and challenges for the treatment of ischemia. Cytokine 71, 385-393. doi: 10.1016/j.cyto.2014. 08.005

Davidson, S. M., and Yellon, D. M. (2018). Exosomes and cardioprotection a critical analysis. Mol. Aspects Med. 60, 104-114. doi: 10.1016/j.mam.2017. 11.004

Ding, Y., Zhao, A. S., Liu, T., Wang, Y. N., Gao, Y., Li, J. A., et al. (2020). An injectable nanocomposite hydrogel for potential application of vascularization and tissue repair. Ann. Biomed. Eng. 48, 1511-1523. doi: 10.1007/s10439-02002471-7

Dong, Z., Guo, J., Xing, X., Zhang, X., Du, Y., and Lu, Q. (2017). RGD modified and PEGylated lipid nanoparticles loaded with puerarin: formulation, characterization and protective effects on acute myocardial ischemia model. Biomed. Pharmacother. 89, 297-304. doi: 10.1016/j.biopha.2017. 02.029

\section{ACKNOWLEDGMENTS}

The authors would like to thank Drs. Jianyi Zhang and Gangjian Qin in The University of Alabama at Birmingham for their continued support.

Ebabe Elle, R., Gaillet, S., Vide, J., Romain, C., Lauret, C., Rugani, N., et al. (2013). Dietary exposure to silver nanoparticles in Sprague-Dawley rats: effects on oxidative stress and inflammation. Food Chem. Toxicol. 60, 297-301. doi: 10.1016/j.fct.2013.07.071

Egwim, C., Dixon, B., Ambrosy, A. P., and Mentz, R. J. (2017). Global variations in patient populations and outcomes in heart failure clinical trials. Curr. Heart Fail Rep. 14, 30-39. doi: 10.1007/s11897-017-0316-1

El Shaer, S. S., Salaheldin, T. A., Saied, N. M., and Abdelazim, S. M. (2017). In vivo ameliorative effect of cerium oxide nanoparticles in isoproterenolinduced cardiac toxicity. Exp. Toxicol. Pathol. 69, 435-441. doi: 10.1016/j.etp. 2017.03.001

Fan, C., Tang, Y., Zhao, M., Lou, X., Pretorius, D., Menasche, P., et al. (2020). CHIR99021 and fibroblast growth factor 1 enhance the regenerative potency of human cardiac muscle patch after myocardial infarction in mice. J. Mol. Cell Cardiol. 141, 1-10. doi: 10.1016/j.yjmcc.2020.03.003

Faraday, M. (1857). The bakerian lecture: experimental relations of gold (and other metals) to light. Philos. Trans. R. Soc. Lond. 147, 145-181. doi: 10.1098/rstl. 1857.0011

Feng, L., Zhang, S., and Liu, Z. (2011). Graphene based gene transfection. Nanoscale 3, 1252-1257.

Ferreira, M. P., Ranjan, S., Correia, A. M., Makila, E. M., Kinnunen, S. M., Zhang, H., et al. (2016). In vitro and in vivo assessment of heart-homing porous silicon nanoparticles. Biomaterials 94, 93-104. doi: 10.1016/j.biomaterials.2016.03.046

Ferreira, M. P. A., Ranjan, S., Kinnunen, S., Correia, A., Talman, V., Makila, E., et al. (2017). Drug-loaded multifunctional nanoparticles targeted to the endocardial layer of the injured heart modulate hypertrophic signaling. Small 13:1701276. doi: $10.1002 / \mathrm{smll} .201701276$

Feynman, R. (1960). There's plenty of room at the bottom. Caltech Eng. Sci. 23, $22-36$.

Fredman, G., Kamaly, N., Spolitu, S., Milton, J., Ghorpade, D., Chiasson, R., et al. (2015). Targeted nanoparticles containing the proresolving peptide Ac226 protect against advanced atherosclerosis in hypercholesterolemic mice. Sci. Transl. Med. 7:275ra220.

Galagudza, M. M., Korolev, D. V., Sonin, D. L., Postnov, V. N., Papayan, G. V., Uskov, I. S., et al. (2010). Targeted drug delivery into reversibly injured myocardium with silica nanoparticles: surface functionalization, natural biodistribution, and acute toxicity. Int. J. Nanomed. 5, 231-237.

Gao, L. R., Pei, X. T., Ding, Q. A., Chen, Y., Zhang, N. K., Chen, H. Y., et al. (2013). A critical challenge: dosage-related efficacy and acute complication intracoronary injection of autologous bone marrow mesenchymal stem cells in acute myocardial infarction. Int. J. Cardiol. 168, 3191-3199. doi: 10.1016/ j.ijcard.2013.04.112

Geim, A. K., and Novoselov, K. S. (2007). The rise of graphene. Nat. Mater. 6, 183-191. doi: 10.1038/nmat1849

Ghasemiyeh, P., and Mohammadi-Samani, S. (2018). Solid lipid nanoparticles and nanostructured lipid carriers as novel drug delivery systems: applications, advantages and disadvantages. Res. Pharm. Sci. 13, 288-303.

Gorain, B., Choudhury, H., Pandey, M., Kesharwani, P., Abeer, M. M., Tekade, R. K., et al. (2018). Carbon nanotube scaffolds as emerging nanoplatform for myocardial tissue regeneration: a review of recent developments and therapeutic implications. Biomed. Pharmacother. 104, 496-508. doi: 10.1016/ j.biopha.2018.05.066

Han, J., Kim, B., Shin, J. Y., Ryu, S., Noh, M., Woo, J., et al. (2015). Iron oxide nanoparticle-mediated development of cellular gap junction crosstalk to improve mesenchymal stem cells' therapeutic efficacy for myocardial infarction. ACS Nano 9, 2805-2819. doi: 10.1021/nn506732n

Han, J., Kim, Y. S., Lim, M. Y., Kim, H. Y., Kong, S., Kang, M., et al. (2018). Dual roles of graphene oxide to attenuate inflammation and elicit timely polarization of macrophage phenotypes for cardiac repair. ACS Nano 12, 1959-1977. doi: 10.1021/acsnano.7b09107 
Haque, S. T., and Chowdhury, E. H. (2018). Recent progress in delivery of therapeutic and imaging agents utilizing organic-inorganic hybrid nanoparticles. Curr. Drug Deliv. 15, 485-496. doi: 10.2174/ 1567201814666171120114034

Harish, K. K., Nagasamy, V., Himangshu, B., and Anuttam, K. (2018). Metallic nanoparticle: a review. Biomed. J. Sci. Tech. Res. 4, 3765-3775.

Ichimura, K., Matoba, T., Nakano, K., Tokutome, M., Honda, K., Koga, J., et al. (2016). A translational study of a new therapeutic approach for acute myocardial infarction: nanoparticle-mediated delivery of pitavastatin into reperfused myocardium reduces ischemia-reperfusion injury in a preclinical porcine model. PLoS One 11:e0162425. doi: 10.1371/journal.pone.0162425

Ikeda, G., Matoba, T., Nakano, Y., Nagaoka, K., Ishikita, A., Nakano, K., et al. (2016). Nanoparticle-mediated targeting of cyclosporine a enhances cardioprotection against ischemia-reperfusion injury through inhibition of mitochondrial permeability transition pore opening. Sci. Rep. 6:20467.

Jeevanandam, J., Barhoum, A., Chan, Y. S., Dufresne, A., and Danquah, M. K. (2018). Review on nanoparticles and nanostructured materials: history, sources, toxicity and regulations. Beilstein J. Nanotechnol. 9, 1050-1074. doi: 10.3762/ bjnano.9.98

Kamaly, N., Fredman, G., Fojas, J. J., Subramanian, M., Choi, W. I., Zepeda, K., et al. (2016). Targeted Interleukin-10 nanotherapeutics developed with a microfluidic chip enhance resolution of inflammation in advanced atherosclerosis. ACS Nano 10, 5280-5292. doi: 10.1021/acsnano.6b01114

Kanki, S., Jaalouk, D. E., Lee, S., Yu, A. Y., Gannon, J., and Lee, R. T. (2011). Identification of targeting peptides for ischemic myocardium by in vivo phage display. J. Mol. Cell Cardiol. 50, 841-848. doi: 10.1016/j.yjmcc.2011.02.003

Katsuki, S., Matoba, T., Koga, J. I., Nakano, K., and Egashira, K. (2017). Antiinflammatory nanomedicine for cardiovascular disease. Front. Cardiovasc. Med. 4:87. doi: $10.3389 /$ fcvm.2017.00087

Ke, Y., Castro, C., and Choi, J. H. (2018). Structural DNA nanotechnology: artificial nanostructures for biomedical research. Annu. Rev. Biomed. Eng. 20, 375-401. doi: 10.1146/annurev-bioeng-062117-120904

Lakshmanan, R., and Maulik, N. (2018). Development of next generation cardiovascular therapeutics through bio-assisted nanotechnology. J. Biomed. Mater. Res. B Appl. Biomater. 106, 2072-2083. doi: 10.1002/jbm.b.34000

Lee, D. S., Qian, H., Tay, C. Y., and Leong, D. T. (2016). Cellular processing and destinies of artificial DNA nanostructures. Chem. Soc. Rev. 45, 4199-4225. doi: $10.1039 / \mathrm{c} 5 \mathrm{cs} 00700 \mathrm{c}$

Lin, C. X., Yang, S. Y., Gu, J. L., Meng, J., Xu, H. Y., and Cao, J. M. (2017). The acute toxic effects of silver nanoparticles on myocardial transmembrane potential, INa and IK1 channels and heart rhythm in mice. Nanotoxicology 11, 827-837.

Lloyd-Jones, D. M., Hong, Y., Labarthe, D., Mozaffarian, D., Appel, L. J., Van Horn, L., et al. (2010). Defining and setting national goals for cardiovascular health promotion and disease reduction: the American Heart Association's strategic Impact Goal through 2020 and beyond. Circulation 121, 586-613. doi: 10.1161/circulationaha.109.192703

Lu, W., Xie, Z., Tang, Y., Bai, L., Yao, Y., Fu, C., et al. (2015). Photoluminescent mesoporous silicon nanoparticles with siCCR2 improve the effects of mesenchymal stromal cell transplantation after acute myocardial infarction. Theranostics 5, 1068-1082. doi: 10.7150/thno.11517

Madigan, M., and Atoui, R. (2018). Therapeutic use of stem cells for myocardial infarction. Bioengineering (Basel) 5:28. doi: 10.3390/bioengineering5020028

Mahmoudi, M., Yu, M., Serpooshan, V., Wu, J. C., Langer, R., Lee, R. T., et al. (2017). Multiscale technologies for treatment of ischemic cardiomyopathy. Nat. Nanotechnol. 12, 845-855. doi: 10.1038/nnano.2017.167

Mao, Y., Koga, J. I., Tokutome, M., Matoba, T., Ikeda, G., Nakano, K., et al. (2017). Nanoparticle-mediated delivery of pitavastatin to monocytes/macrophages inhibits left ventricular remodeling after acute myocardial infarction by inhibiting monocyte-mediated inflammation. Int. Heart J. 58, 615-623. doi: 10.1536/ihj.16-457

Martinelli, V., Cellot, G., Toma, F. M., Long, C. S., Caldwell, J. H., Zentilin, L., et al. (2013). Carbon nanotubes instruct physiological growth and functionally mature syncytia: nongenetic engineering of cardiac myocytes. ACS Nano 7, 5746-5756. doi: 10.1021/nn4002193

Miragoli, M., Ceriotti, P., Iafisco, M., Vacchiano, M., Salvarani, N., Alogna, A., et al. (2018). Inhalation of peptide-loaded nanoparticles improves heart failure. Sci. Transl. Med. 10:eaan6205. doi: 10.1126/scitranslmed.aan6205
Morgan, M. T., Carnahan, M. A., Finkelstein, S., Prata, C. A., Degoricija, L., Lee, S. J., et al. (2005). Dendritic supramolecular assemblies for drug delivery. Chem. Commun. (Camb) 2005, 4309-4311.

Nagaoka, K., Matoba, T., Mao, Y., Nakano, Y., Ikeda, G., Egusa, S., et al. (2015). A new therapeutic modality for acute myocardial infarction: nanoparticlemediated delivery of pitavastatin induces cardioprotection from ischemiareperfusion injury via activation of PI3K/Akt pathway and anti-inflammation in a rat model. PLoS One 10:e0132451. doi: 10.1371/journal.pone.0132451

Nakano, Y., Matoba, T., Tokutome, M., Funamoto, D., Katsuki, S., Ikeda, G., et al. (2016). Nanoparticle-mediated delivery of irbesartan induces cardioprotection from myocardial ischemia-reperfusion injury by antagonizing monocytemediated inflammation. Sci. Rep. 6:29601.

Namdari, M., Cheraghi, M., Negahdari, B., Eatemadi, A., and Daraee, H. (2017). Recent advances in magnetoliposome for heart drug delivery. Artif. Cells Nanomed. Biotechnol. 45, 1-7.

Nguyen, J., Sievers, R., Motion, J. P., Kivimae, S., Fang, Q., and Lee, R. J. (2015). Delivery of lipid micelles into infarcted myocardium using a lipid-linked matrix metalloproteinase targeting peptide. Mol. Pharm. 12, 1150-1157. doi: 10.1021/ mp500653y

Nguyen, M. M., Carlini, A. S., Chien, M. P., Sonnenberg, S., Luo, C., Braden, R. L., et al. (2015). Enzyme-responsive nanoparticles for targeted accumulation and prolonged retention in heart tissue after myocardial infarction. Adv. Mater. 27, 5547-5552. doi: 10.1002/adma.201502003

Niu, J., Azfer, A., Rogers, L. M., Wang, X., and Kolattukudy, P. E. (2007). Cardioprotective effects of cerium oxide nanoparticles in a transgenic murine model of cardiomyopathy. Cardiovasc. Res. 73, 549-559. doi: 10.1016/j. cardiores.2006.11.031

Niu, J., Wang, K., and Kolattukudy, P. E. (2011). Cerium oxide nanoparticles inhibit oxidative stress and nuclear factor-kappaB activation in $\mathrm{H} 9 \mathrm{c} 2$ cardiomyocytes exposed to cigarette smoke extract. J. Pharmacol. Exp. Ther. 338, 53-61. doi: 10.1124/jpet.111.179978

Novoselov, K. S., Geim, A. K., Morozov, S. V., Jiang, D., Zhang, Y., Dubonos, S. V., et al. (2004). Electric field effect in atomically thin carbon films. Science 306, 666-669. doi: 10.1126/science.1102896

Oduk, Y., Zhu, W., Kannappan, R., Zhao, M., Borovjagin, A. V., Oparil, S., et al. (2018). VEGF nanoparticles repair the heart after myocardial infarction. Am. J. Physiol. Heart Circ. Physiol. 314, H278-H284.

Oggu, G. S., Sasikumar, S., Reddy, N., Ella, K. K. R., Rao, C. M., and Bokara, K. K. (2017). Gene delivery approaches for mesenchymal stem cell therapy: strategies to increase efficiency and specificity. Stem Cell Rev. 13, 725-740. doi: 10.1007/s12015-017-9760-2

Ottersbach, A., Mykhaylyk, O., Heidsieck, A., Eberbeck, D., Rieck, S., Zimmermann, K., et al. (2018). Improved heart repair upon myocardial infarction: combination of magnetic nanoparticles and tailored magnets strongly increases engraftment of myocytes. Biomaterials 155, 176-190. doi: 10.1016/j.biomaterials.2017.11.012

Pan, K., and Zhong, Q. (2016). Organic nanoparticles in foods: fabrication, characterization, and utilization. Annu. Rev. Food Sci. Technol. 7, 245-266. doi: 10.1146/annurev-food-041715-033215

Pandey, P., and Dahiya, M. (2016). A brief review on inorganic nanoparticles. J. Crit. Rev. 3, 18-26.

Park, J., Kim, B., Han, J., Oh, J., Park, S., Ryu, S., et al. (2015). Graphene oxide flakes as a cellular adhesive: prevention of reactive oxygen species mediated death of implanted cells for cardiac repair. ACS Nano 9, 4987-4999. doi: $10.1021 / \mathrm{nn} 507149 \mathrm{w}$

Pascual-Gil, S., Simon-Yarza, T., Garbayo, E., Prosper, F., and Blanco-Prieto, M. J. (2017). Cytokine-loaded PLGA and PEG-PLGA microparticles showed similar heart regeneration in a rat myocardial infarction model. Int. J. Pharm. 523, 531-533. doi: 10.1016/j.ijpharm.2016.11.022

Paul, A., Binsalamah, Z. M., Khan, A. A., Abbasia, S., Elias, C. B., Shum-Tim, D., et al. (2011). A nanobiohybrid complex of recombinant baculovirus and Tat/DNA nanoparticles for delivery of Ang-1 transgene in myocardial infarction therapy. Biomaterials 32, 8304-8318. doi: 10.1016/j.biomaterials.2011.07.042

Paul, A., Hasan, A., Kindi, H. A., Gaharwar, A. K., Rao, V. T., Nikkhah, M., et al. (2014). Injectable graphene oxide/hydrogel-based angiogenic gene delivery system for vasculogenesis and cardiac repair. ACS Nano 8, 8050-8062. doi: $10.1021 / \mathrm{nn} 5020787$ 
Paulis, L. E., Geelen, T., Kuhlmann, M. T., Coolen, B. F., Schafers, M., Nicolay, K., et al. (2012). Distribution of lipid-based nanoparticles to infarcted myocardium with potential application for MRI-monitored drug delivery. J. Control Release 162, 276-285. doi: 10.1016/j.jconrel.2012.06.035

Pearson, R. M., Sunoqrot, S., Hsu, H. J., Bae, J. W., and Hong, S. (2012). Dendritic nanoparticles: the next generation of nanocarriers? Ther. Deliv. 3, 941-959. doi: $10.4155 /$ tde. 12.76

Pitroda, J., Jethwa, B., and Dave, S. K. (2016). A critical review on carbon nanotubes. Int. J. Construct. Res. Civil Eng. 2, 36-42.

Potter, L. R., Yoder, A. R., Flora, D. R., Antos, L. K., and Dickey, D. M. (2009). Natriuretic peptides: their structures, receptors, physiologic functions and therapeutic applications. Handb. Exp. Pharmacol. 191, 341-366. doi: 10.1007/ 978-3-540-68964-5_15

Priyadarsini, S., Mukherjee, S., and Mishra, M. (2018). Nanoparticles used in dentistry: a review. J. Oral Biol. Craniofac. Res. 8, 58-67. doi: 10.1016/j.jobcr. 2017.12.004

Qi, J., Zhuang, J., Lu, Y., Dong, X., Zhao, W., and Wu, W. (2017). In vivo fate of lipid-based nanoparticles. Drug Discov. Today 22, 166-172. doi: 10.1016/j. drudis.2016.09.024

Qi, Q., Lu, L., Li, H., Yuan, Z., Chen, G., Lin, M., et al. (2017). Spatiotemporal delivery of nanoformulated liraglutide for cardiac regeneration after myocardial infarction. Int. J. Nanomed. 12, 4835-4848. doi: 10.2147/ijn.s132064

Raphey, V. R., Henna, T. K., Nivitha, K. P., Mufeedha, P., Sabu, C., and Pramod, K. (2019). Advanced biomedical applications of carbon nanotube. Mater. Sci. Eng. C Mater. Biol. Appl. 100, 616-630.

Reboucas, J. S., Santos-Magalhaes, N. S., and Formiga, F. R. (2016). Cardiac regeneration using growth factors: advances and challenges. Arq. Bras Cardiol. 107, 271-275.

Sager, H. B., Dutta, P., Dahlman, J. E., Hulsmans, M., Courties, G., Sun, Y., et al. (2016). RNAi targeting multiple cell adhesion molecules reduces immune cell recruitment and vascular inflammation after myocardial infarction. Sci. Transl. Med. 8:342ra380.

Sajid, M. I., Jamshaid, U., Jamshaid, T., Zafar, N., Fessi, H., and Elaissari, A. (2016). Carbon nanotubes from synthesis to in vivo biomedical applications. Int. J. Pharm. 501, 278-299. doi: 10.1016/j.ijpharm.2016.01.064

Saludas, L., Pascual-Gil, S., Roli, F., Garbayo, E., and Blanco-Prieto, M. J. (2018). Heart tissue repair and cardioprotection using drug delivery systems. Maturitas 110, 1-9. doi: 10.1016/j.maturitas.2018.01.011

Samidurai, A., Salloum, F. N., Durrant, D., Chernova, O. B., Kukreja, R. C., and Das, A. (2017). Chronic treatment with novel nanoformulated micelles of rapamycin, Rapatar, protects diabetic heart against ischaemia/reperfusion injury. Br. J. Pharmacol. 174, 4771-4784. doi: 10.1111/bph.14059

Saravanan, S., Sareen, N., Abu-El-Rub, E., Ashour, H., Sequiera, G. L., Ammar, H. I., et al. (2018). Graphene oxide-gold nanosheets containing chitosan scaffold improves ventricular contractility and function after implantation into infarcted heart. Sci. Rep. 8:15069.

Shao, M., Yang, W., and Han, G. (2017). Protective effects on myocardial infarction model: delivery of schisandrin B using matrix metalloproteinase-sensitive peptide-modified, PEGylated lipid nanoparticles. Int. J. Nanomed. 12, 71217130. doi: 10.2147/ijn.s141549

Sharma, A. K., Kumar, A., Sahu, M., Sharma, G., Datusalia, A. K., and Rajput, S. K. (2018). Exercise preconditioning and low dose copper nanoparticles exhibits cardioprotection through targeting GSK-3beta phosphorylation in ischemia/reperfusion induced myocardial infarction. Microvasc. Res. 120, 5966. doi: 10.1016/j.mvr.2018.06.003

Shin, S. R., Jung, S. M., Zalabany, M., Kim, K., Zorlutuna, P., Kim, S. B., et al. (2013). Carbon-nanotube-embedded hydrogel sheets for engineering cardiac constructs and bioactuators. ACS Nano 7, 2369-2380. doi: 10.1021/nn305559j

Singh, B., Garg, T., Goyal, A. K., and Rath, G. (2016). Recent advancements in the cardiovascular drug carriers. Artif. Cells Nanomed. Biotechnol. 44, 216-225. doi: $10.3109 / 21691401.2014 .937868$

Singh, M., Manikandan, S., and Kumaraguru, A. K. (2011). Nanoparticles: a new technology with wide applications. Res. J. Nanosci. Nanotechnol. 1, 1-11. doi: 10.3923/rjnn.2011.1.11

Somasuntharam, I., Boopathy, A. V., Khan, R. S., Martinez, M. D., Brown, M. E., Murthy, N., et al. (2013). Delivery of Nox2-NADPH oxidase siRNA with polyketal nanoparticles for improving cardiac function following myocardial infarction. Biomaterials 34, 7790-7798. doi: 10.1016/j.biomaterials.2013.06.051
Somasuntharam, I., Yehl, K., Carroll, S. L., Maxwell, J. T., Martinez, M. D., Che, P. L., et al. (2016). Knockdown of TNF-alpha by DNAzyme gold nanoparticles as an anti-inflammatory therapy for myocardial infarction. Biomaterials 83, 12-22. doi: 10.1016/j.biomaterials.2015.12.022

Sperling, R. A., Rivera Gil, P., Zhang, F., Zanella, M., and Parak, W. J. (2008). Biological applications of gold nanoparticles. Chem. Soc. Rev. 37, 1896-1908.

Stankovich, S., Dikin, D. A., Dommett, G. H., Kohlhaas, K. M., Zimney, E. J., Stach, E. A., et al. (2006). Graphene-based composite materials. Nature 442, 282-286.

Sun, H., Tang, J., Mou, Y., Zhou, J., Qu, L., Duval, K., et al. (2017a). Carbon nanotube-composite hydrogels promote intercalated disc assembly in engineered cardiac tissues through betal-integrin mediated FAK and RhoA pathway. Acta Biomater. 48, 88-99. doi: 10.1016/j.actbio.2016.10.025

Sun, H., Zhou, J., Huang, Z., Qu, L., Lin, N., Liang, C., et al. (2017b). Carbon nanotube-incorporated collagen hydrogels improve cell alignment and the performance of cardiac constructs. Int. J. Nanomedicine. 12, 3109-3120. doi: $10.2147 /$ ijn.s128030

Sun, X., Liu, Z., Welsher, K., Robinson, J. T., Goodwin, A., Zaric, S., et al. (2008). Nano-graphene oxide for cellular imaging and drug delivery. Nano Res. 1, 203-212. doi: 10.1007/s12274-008-8021-8

Tan, M. E., He, C. H., Jiang, W., Zeng, C., Yu, N., Huang, W., et al. (2017). Development of solid lipid nanoparticles containing total flavonoid extract from Dracocephalum moldavica L. and their therapeutic effect against myocardial ischemia-reperfusion injury in rats. Int. J. Nanomed. 12, 3253-3265. doi: 10.2147/ijn.s131893

Tang, C., Li, H., Hong, J., and Chai, X. (2020). Application of nanoparticles in the early diagnosis and treatment of tumors: current status and progress. Trad. Med. Res. 5, 34-43.

Tateishi-Yuyama, E., Matsubara, H., Murohara, T., Ikeda, U., Shintani, S., Masaki, H., et al. (2002). Therapeutic angiogenesis for patients with limb ischaemia by autologous transplantation of bone-marrow cells: a pilot study and a randomised controlled trial. Lancet 360, 427-435. doi: 10.1016/s0140-6736(02) 09670-8

Terashvili, M., and Bosnjak, Z. J. (2019). Stem cell therapies in cardiovascular disease. J. Cardiothorac. Vasc. Anesth. 33, 209-222.

Thomas, T. P., Joice, M., Sumit, M., Silpe, J. E., Kotlyar, A., Bharathi, S., et al. (2013). Design and in vitro validation of multivalent dendrimer methotrexates as a folate-targeting anticancer therapeutic. Curr. Pharm. Des. 19, 6594-6605. doi: 10.2174/1381612811319370004

Tian, A., Yang, C., Zhu, B., Wang, W., Liu, K., Jiang, Y., et al. (2018). Polyethyleneglycol-coated gold nanoparticles improve cardiac function after myocardial infarction in mice. Can. J. Physiol. Pharmacol. 96, 1318-1327. doi: 10.1139/ cjpp-2018-0227

Vinhas, R., Mendes, R., Fernandes, A. R., and Baptista, P. V. (2017). Nanoparticlesemerging potential for managing leukemia and lymphoma. Front. Bioeng. Biotechnol. 5:79. doi: 10.3389/fbioe.2017.00079

Virlan, M. J., Miricescu, D., Radulescu, R., Sabliov, C. M., Totan, A., Calenic, B., et al. (2016). Organic nanomaterials and their applications in the treatment of oral diseases. Molecules 21:207. doi: 10.3390/molecules21020207

Vong, L. B., Bui, T. Q., Tomita, T., Sakamoto, H., Hiramatsu, Y., and Nagasaki, Y. (2018). Novel angiogenesis therapeutics by redox injectable hydrogel regulation of local nitric oxide generation for effective cardiovascular therapy. Biomaterials 167, 143-152. doi: 10.1016/j.biomaterials.2018.03.023

Wang, J., Seo, M. J., Deci, M. B., Weil, B. R., Canty, J. M., and Nguyen, J. (2018). Effect of CCR2 inhibitor-loaded lipid micelles on inflammatory cell migration and cardiac function after myocardial infarction. Int. J. Nanomed. 13, 6441-6451. doi: 10.2147/ijn.s178650

Xu, Q. H., Guan, P., Zhang, T., Lu, C., Li, G., and Liu, J. X. (2018). Silver nanoparticles impair zebrafish skeletal and cardiac myofibrillogenesis and sarcomere formation. Aquat. Toxicol. 200, 102-113. doi: 10.1016/j.aquatox. 2018.04.018

Xue, X., Shi, X., Dong, H., You, S., Cao, H., Wang, K., et al. (2018). Delivery of microRNA-1 inhibitor by dendrimer-based nanovector: an early targeting therapy for myocardial infarction in mice. Nanomedicine 14, 619-631. doi: 10.1016/j.nano.2017.12.004

Yang, J., Brown, M. E., Zhang, H., Martinez, M., Zhao, Z., Bhutani, S., et al. (2017). High-throughput screening identifies microRNAs that target Nox 2 and improve function after acute myocardial infarction. Am. J. Physiol. Heart Circ. Physiol. 312, H1002-H1012. 
Yin, Q., Pei, Z., Wang, H., and Zhao, Y. (2014). Cyclosporine A-nanoparticles enhance the therapeutic benefit of adipose tissue-derived stem cell transplantation in a swine myocardial infarction model. Int. J. Nanomed. 9, 17-26.

Zanganeh, S., Hutter, G., Spitler, R., Lenkov, O., Mahmoudi, M., Shaw, A., et al. (2016). Iron oxide nanoparticles inhibit tumour growth by inducing proinflammatory macrophage polarization in tumour tissues. Nat. Nanotechnol. 11, 986-994. doi: 10.1038/nnano.2016.168

Zhang, L., Xia, J., Zhao, Q., Liu, L., and Zhang, Z. (2010). Functional graphene oxide as a nanocarrier for controlled loading and targeted delivery of mixed anticancer drugs. Small 6, 537-544. doi: 10.1002/smll.200901680

Zhang, S., Wang, J., and Pan, J. (2016). Baicalin-loaded PEGylated lipid nanoparticles: characterization, pharmacokinetics, and protective effects on acute myocardial ischemia in rats. Drug Deliv. 23, 3696-3703. doi: 10.1080/ 10717544.2016.1223218

Zhang, W., Zhang, Z., and Zhang, Y. (2011). The application of carbon nanotubes in target drug delivery systems for cancer therapies. Nanoscale Res. Lett. 6:555.

Zhou, J., Yang, X., Liu, W., Wang, C., Shen, Y., Zhang, F., et al. (2018). Injectable $\mathrm{OPF} /$ graphene oxide hydrogels provide mechanical support and enhance cell electrical signaling after implantation into myocardial infarct. Theranostics 8 , 3317-3330. doi: 10.7150/thno.25504

Zhou, J., and Zhang, G. (2019). Antitumor applications of nano-traditional Chinese medicine. Trad. Med. Res. 4, 224-226.
Zhou, L. S., Zhao, G. L., Liu, Q., Jiang, S. C., Wang, Y., and Zhang, D. M. (2015). Silencing collapsin response mediator protein-2 reprograms macrophage phenotype and improves infarct healing in experimental myocardial infarction model. J. Inflamm. (Lond.) 12:11. doi: 10.1186/s12950-015-0053-8

Zhou, Y., Sun, H., Xu, H., Matysiak, S., Ren, J., and Qu, X. (2018). Mesoporous encapsulated chiral nanogold for use in enantioselective reactions. Angew. Chem. Int. Ed. Engl. 57, 16791-16795. doi: 10.1002/anie.20181 1118

Zhu, K., Wu, M., Lai, H., Guo, C., Li, J., Wang, Y., et al. (2016). Nanoparticleenhanced generation of gene-transfected mesenchymal stem cells for in vivo cardiac repair. Biomaterials 74, 188-199. doi: 10.1016/j.biomaterials.2015. 10.010

Conflict of Interest: The authors declare that the research was conducted in the absence of any commercial or financial relationships that could be construed as a potential conflict of interest.

Copyright (c) 2020 Fan, Joshi, Li, Xu, Khan, Yang and Zhu. This is an open-access article distributed under the terms of the Creative Commons Attribution License (CC BY). The use, distribution or reproduction in other forums is permitted, provided the original author(s) and the copyright owner(s) are credited and that the original publication in this journal is cited, in accordance with accepted academic practice. No use, distribution or reproduction is permitted which does not comply with these terms. 